\title{
A Two Year Retrospective Study of Direct Immunofluorescence in Autoimmune Vesiculobullous Lesions with Clinical Correlation
}

\section{ABSTRACT}

Introduction: Autoimmune bullous lesions are diverse group of diseases characterised by blisters in the skin with or without mucosal lesions. They present with great degree of clinical and histopathological overlap; hence, advanced immunological methods like direct and indirect immunofluorescence techniques have become essential for accurate diagnosis in most of these cases.

Aim: To study the pattern, intensity of immunofluorescence among various autoimmune vesiculobullous lesions with clinical correlation.

Materials and Methods: This present study was a retrospective one in which 36 cases of vesiculobullous lesions were included. In Direct Immuno Fluorescence (DIF) the type of immunoglobulin expressed, pattern of deposition and its intensity was noted. Statistical method was used to calculate percentages, ratio, sensitivity and specificity.
Results: The mean age in the study group was 46.2 years $(\mathrm{SD} \pm 17.9)$ with male to female ratio 1.2:1. Most common lesion was pemphigus vulgaris in $12(33.3 \%)$ cases. Most common site of the lesions were trunk 11 cases $(30.5 \%)$, followed by upper extremity in 8 cases $(22.2 \%)$. Only in 8 (22.2\%) cases histopathological correlation was done. DIF was positive in 31 cases (86.1\%). IgG was present in 25 (69.4\%) patients, C3 was positive in 14 (38.8\%) cases and IgM was present in $6(16.6 \%)$ patients. DIF was inconclusive in $5(13.8 \%)$ cases. Intensity of $3+\operatorname{lgG}$ was seen in $2(16.6 \%)$ cases of pemphigus vulgaris followed by $2+$ intensity in $5(41.6 \%)$ cases. C3 was positive in $14(38.8 \%)$ cases with $2+$ expression seen in 4 $(30.4 \%)$ cases.

Conclusion: DIF is a helpful diagnostic test in autoimmune vesiculobullous lesions even in absence of histopathological correlation.

\section{Keywords: Blister, Fluorescent antibody technique, Skin}

\section{INTRODUCTION}

Cutaneous autoimmune non-infectious vesiculobullous diseases are a group of uncommon disorders, characterised by presence of autoantibodies against epithelial and mucosal intercellular antigens. Incidence varies from 0.09 to $1.8 \%$ in India [1]. Due to their overlapping clinical and histological features, many times they are source of diagnostic dilemma. So adjunctive Immuno-fluorescence (IF) method plays a crucial role in the diagnosis of these lesions. IF is a histochemical staining technique which detects antibodies in the tissue and body fluids. It not only aids in diagnosis, also helps in monitoring disease activity and predicting relapse [2,3]. IF is of three types; direct, indirect and complement indirect method. Direct IF (DIF) is a one-step method in which Fluorescein isothiocyanate (FITC) conjugates are applied over patient's skin biopsy which detects antibodies against skin giving highly specific and low false positive results. Indirect IF in contrast is a two-step technique using patient's serum. Though it is sensitive, rate of false positive results are also high. Complement indirect method is a three step procedure assessing complement binding ability of autoantibodies, so making it most specific method [4]. The aim of this study was to analyse the pattern, intensity and contribution of IF in diagnosis of various autoimmune vesiculobullous lesions with clinical correlation even in absence of histopathological study.

\section{MATERIALS AND METHODS}

This was a retrospective study undertaken between April 2017 to May 2019 including 36 patients with vesiculobullous lesions attending the Department of Dermatology and Venereology, AlIMS, Bhubaneswar, Odisha, India, who were advised for DIF study. The study has been conducted according to the guidelines and standard of Helsinki declaration.

\section{A) Inclusion criteria were:}

- All age and sex groups.

- Clinically suspected cases of vesiculobullous lesions/patients with intact blisters.

\section{B) Exclusion criteria were:}

- Subjects with systemic disorders such as diabetes mellitus, haematologic disturbances.

- $\quad$ Physically debilitated subjects.

- $\quad$ Cases with only histology and without IF study $[5,6]$.

The patient's particulars regarding age, gender, personal and treatment history, presenting symptoms, duration of complaints, general and systemic examination findings were noted down from the records. For DIF study, $4 \mathrm{~mm}$ punch biopsies were taken from the perilesional areas and fixed in Michel's transport medium while transferring to frozen section lab. The immuno-reactants included were FITC conjugated rabbit anti-human antisera IgG, IgA, IgM, C3 and fibrinogen (Dako). For histo-pathological study, biopsies had been taken from lesions and sent to Department of Histopathology for routinely processing and staining by haematoxylin and eosin stain for light microscopy to confirm the diagnosis and identify the morphological changes. Tzank smears were done when ever needed.

For DIF study, skin biopsy received in Michel's medium were stored at $4^{\circ} \mathrm{C}$ until cut. Before sectioning, the skin biopsy was brought to room temperature, then washed tree times 
with Phosphate Buffer Saline (PBS). A 4-6 $\mu \mathrm{m}$ sections were cut on cryostat at $-20^{\circ} \mathrm{C}$ and were put in poly-L-lysine coated slides. Two sections were layered on each slide. Slides were then rinsed in PBS ( $\mathrm{pH}$ 7.0-7.2) thrice for 10 minutes to remove surrounding Optimal Cutting Temperature (OCT) compound and kept in a moist chamber. The different FITC conjugates (IgG, $\lg \mathrm{A}, \operatorname{Ig} \mathrm{M}, \mathrm{C} 3$, Fibrinogen) were layered onto the sections and incubated at $37^{\circ} \mathrm{C}$ for $30-45$ minutes. The negative control slide was covered with PBS only. Slides were then washed three times with PBS, each wash lasting for at least 5 minutes to remove unbound antisera and mounted in buffered glycerol mountant ( $\mathrm{pH}$ 6.8). Slides were seen under Leica DM2500 (Leica DFC365FX) immuno-fluorescence microscope and following points were noted:

- $\quad$ Presence or absence of immuno-reactants

- Type of immuno-reactant deposition (IgG,IgA,IgM,C3, Fibrin)

- Intensity of immuno-fluorescence: Semi-quantitative grading of strength of immuno-fluorescence + to ++++

- $\quad$ Site of deposition of immuno-reactants

\section{$\checkmark$ Epidermal intercellular space (ICS)}

$\checkmark$ Epidermal nuclear staining or in-vivo ANA

$\checkmark$ Basement Membrane Zone (BMZ)

$\checkmark$ Dermal vessels or hair shaft or civette bodies etc.,

- Pattern of deposition (linear, granular, discontinuous or a combination of the two) $[3,4]$.

Salt Split Technique (SST): In this technique, after overnight incubation of the patient's skin (direct SST) in $1 \mathrm{M}$ sodium chloride, the skin substrate was gently teased with the use of a fine forcep to separate epidermis from dermis at the level of lamina lucida. After this, the tissue was processed in the same manner as in DIF. Some sub-epidermal bullous lesion show shift of antigens to dermal side i.e., "floor" binding pattern and some retaining the epidermal side of antigen attachment i.e., "roof" binding pattern [7].

\section{STATISTICAL ANALYSIS}

Statistical analysis was done on Microsoft Excel. By using SPSS version 18.0, percentages, ratio, sensitivity and specificity were derived. Categorical variables were expressed as frequencies and percentages.

\section{RESULTS}

During the study period, total 36 cases were received for DIF study. Autoimmune vesiculobullous disorders were found to be more common in males with male to female ratio 1.2:1. The age ranged from 1-70 years with mean age 46.2 years $(S D \pm 17.9)$. Maximum patients 10 (27.7\%) belonged to 31-50 years age group. Most common lesion in our study was pemphigus vulgaris, including 12 (33.3\%) cases [Table/Fig-1]. About 19 (54.6\%) patients presented with flaccid vesicles and $10(28.7 \%)$ presented with tense bullae. Most of the lesions were located in trunk 11 (30.5\%), followed by upper extremity 8 (22.2\%) [Table/Fig-2]. Tzanck smear was positive for acantholytic cells in only $13(48.5 \%)$ of cases [Table/Fig-3]. Bullae were located sub-epidermally in 12 (30.5\%) of patients and intra-epidermally in $21(61.1 \%)$ of patients [Table/Fig-4]. No bullae were seen in 3 (8.3\%) of cases. DIF was positive in 31 cases $(86.1 \%)$ of vesiculobullous disorders. Only in $8(22.2 \%)$ cases, histopathological correlation could be done. Of the 31 patients who were found to have positive DIF study, IgG was present in 25 (69.4\%) patients, C3 was present in 14 (38.8\%) cases, IgM was present in 6 (16.6\%) patients [Table/Fig-5]. DIF was inconclusive in $5(13.8 \%)$ cases. Intensity of $3+$ was seen in $2(16.6 \%)$ cases of pemphigus vulgaris followed by $2+$ intensity in 5 (41.6\%) cases and $1+$ intensity in the remaining 5 cases (41.8\%). Among all cases, C3 expression was positive, 2+ expression was seen in 4 (30.4\%) cases and 10 (65.2\%) cases had $1+$ expression. Sensitivity was $88.8 \%$, specificity was $33.3 \%$, Positive Predictive Value (PPV) and Negative Predictive Value (NPV) was $80 \%$ and $50 \%$ respectively.

\begin{tabular}{|l|c|c|c|}
\hline Clinical diagnosis & $\begin{array}{c}\text { Number } \\
(\%)\end{array}$ & $\begin{array}{c}\text { Age range } \\
\text { (Mean age in yrs) }\end{array}$ & M:F \\
\hline Pemphigus Vulgaris (PV) & $12(33.3 \%)$ & $33-68(45.1)$ & $1.4: 1$ \\
\hline Bullous Pemphigoid (BP) & $7(19.4 \%)$ & $11-70(51.1)$ & $1.3: 1$ \\
\hline Hansens disease & $4(11.1 \%)$ & $34-54(46.2)$ & $1: 1$ \\
\hline Linear IgA Pemphigoid & $3(7.1 \%)$ & $14-68(41.6)$ & $3: 1$ \\
\hline Vasculitis & $2(5.4 \%)$ & $18-45(31.5)$ & $0: 2$ \\
\hline $\begin{array}{l}\text { Chronic Bullous Disorders of } \\
\text { Childhood (CBDC) }\end{array}$ & $2(5.4 \%)$ & $1-61(31)$ & $1: 1$ \\
\hline Cicatricial Pemphigoid (CP) & $1(2.7 \%)$ & $-(65)$ & - \\
\hline Bullous Impetigo (BI) & $1(2.7 \%)$ & $-(61)$ & - \\
\hline Stevens Johnson Syndrome (SJS) & $1(2.7 \%)$ & $-(63)$ & - \\
\hline Dermatitis Herpetiformis (DH) & $1(2.7 \%)$ & $-(43)$ & - \\
\hline Pemphigus Foliaceous (PF) & $1(2.7 \%)$ & $-(33)$ & - \\
\hline Bullous SLE (BSLE) & $1(2.7 \%)$ & $-(27)$ & - \\
\hline [Table/Fig-1]: Frequency of vesiculobullous lesions. & & \\
\hline
\end{tabular}

\begin{tabular}{|l|c|c|c|c|c|c|c|c|}
\hline \multirow{2}{*}{ Diagnosis } & \multicolumn{7}{|c|}{ Number of cases } \\
\cline { 2 - 9 } & $\begin{array}{c}\text { Oral } \\
\text { mucosa }\end{array}$ & Scalp & Trunk & Face & Neck & UE $^{*}$ & LE $^{\dagger}$ & $\begin{array}{c}\text { All } \\
\text { over }\end{array}$ \\
\hline PV & 2 & - & 3 & 1 & 1 & 3 & 2 & - \\
\hline BP & - & - & 1 & - & 2 & 3 & 1 & - \\
\hline CBDC & - & - & 1 & - & - & - & - & 1 \\
\hline $\begin{array}{l}\text { Hansens } \\
\text { disease }\end{array}$ & - & - & 2 & 1 & - & 1 & - & - \\
\hline CP & 1 & - & - & - & - & - & - & - \\
\hline BI & - & - & 1 & - & - & - & - & - \\
\hline SJS & - & 1 & - & - & - & - & - & - \\
\hline PF & - & - & 1 & - & - & - & - & - \\
\hline DH & - & - & - & - & - & 1 & - & - \\
\hline $\begin{array}{l}\text { Linear IgA } \\
\text { Pemphigoid }\end{array}$ & - & - & 2 & - & - & - & 1 & - \\
\hline Vasculitis & - & - & - & - & - & - & 2 & - \\
\hline BSLE & - & - & - & 1 & - & - & - & - \\
\hline Total (36) & $8.1 \%$ & $2.7 \%$ & $30.5 \%$ & $8.1 \%$ & $8.1 \%$ & $22.2 \%$ & $16.6 \%$ & $2.7 \%$ \\
\hline $\begin{array}{l}\text { [Table/Fig-2]: Site distribution of vesiculobullous lesions. } \\
\text { *UE: Upper extremity; }{ }^{+} \text {LE: Lower extremity }\end{array}$ &
\end{tabular}

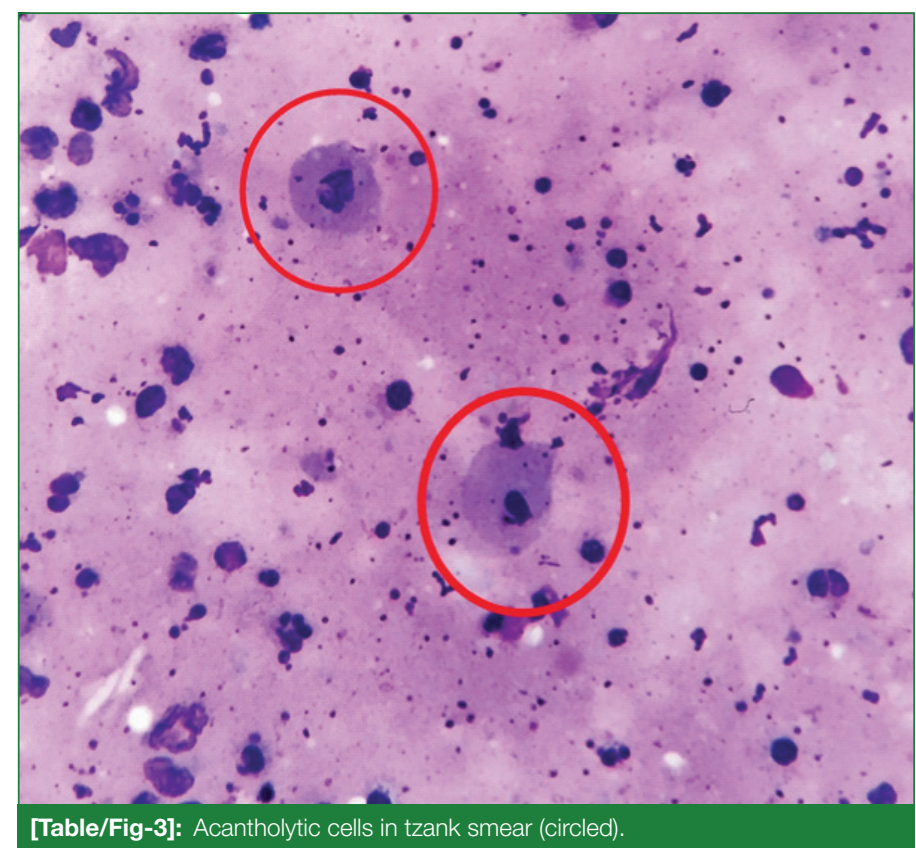




\begin{tabular}{|l|c|c|c|c|c|}
\hline \multirow{2}{*}{ Diseases } & \multicolumn{5}{|c|}{ Number of cases } \\
\cline { 2 - 6 } & $\begin{array}{c}\text { Squamous } \\
\text { ICS }\end{array}$ & DEJs & Both & Dermal vessels & Negative \\
\hline PV & 9 & 0 & 1 & - & 2 \\
\hline BP & - & 7 & - & - & - \\
\hline CBDC & 1 & 1 & - & - & - \\
\hline $\begin{array}{l}\text { Hansens } \\
\text { disease }\end{array}$ & 1 & 2 & - & - & 1 \\
\hline CP & 1 & - & - & - & - \\
\hline Bl & - & 1 & - & - & - \\
\hline SJS & - & - & - & - & 1 \\
\hline PF & - & 1 & - & - & - \\
\hline DH & - & 1 & - & - & - \\
\hline $\begin{array}{l}\text { Linear IgA } \\
\text { Pemphigoid }\end{array}$ & - & 2 & - & - & 1 \\
\hline BSLE & - & 1 & - & - & - \\
\hline Vasculitis & - & - & - & 2 & $13.8 \%$ \\
\hline Total (36) & $33.3 \%$ & $44.4 \%$ & $2.7 \%$ & $5.4 \%$ & \\
\hline [Table/Fig-4]: Site of antibody deposition in DIF. \\
flCS-Intercellular space; \$DEJ- Dermoepidermal junction
\end{tabular}

\section{DISCUSSION}

Immunofluorescence was first developed by Coon in the 1940s with the blue B-fluorescent compound, anthracene. Diagnostic immuno-fluorescence in dermatology started in 1963 with Lupus Band Test (LBT). Since then IF has become an indispensable part of a dermatopathology laboratory [4].

In present study, $27.7 \%$ of patients belonged to $31-50$ years age group, similar to Kabir AKM Nurul et al., but Arya SR et al., had different finding with maximum number of patients belong to 21-60 years $[8,9]$. The mean age of study population was $46.2(\mathrm{SD} \pm 17.9)$ years in the current study. This is in accordance with a study by

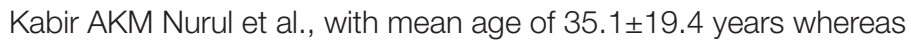
study by Buch AC et al., described mean age of 57 years $[8,10]$. There was overall male predominance in this study. Out of 36 cases studied, 22 patients (55.5\%) were males and 16 patients (44.4\%) were females with a male to female ratio of $1.2: 1$

Predominant sites of involvement of vesiculo-bullous lesions in present study were the trunk (30.5\%), followed by upper extremity (22.2\%). Similar observations by Shafi $\mathrm{M}$ et al., state trunk and extremities are frequently involved sites in most of the cases [11]. Oral mucosa was involved in two Pemphigus Vulgaris and one Cicatricial Pemphigoid case. This showed results similar to Arundhathi $S$ et al., in which oral mucosal involvement was seen in $84.6 \%$ cases in pemphigus vulgaris and $18.2 \%$ cases in bullous pemphigoid [12]. Choosing a proper biopsy site for DIF study is extremely important as it may cause false positive or false negative result.
This study consisted of 12 (33.3\%) cases of pemphigus vulgaris, seven cases of bullous pemphigoid (19.4\%), four cases of hansens disease (11.1\%), 3 cases of linear IgA pemphigoid (7.1\%), one case of dermatitis herpetiformis [Table/Fig-6], two cases of vasculitis (5.4\%) [Table/Fig-7]. Pemphigus vulgaris was the most common bullous disease followed by bullous pemphigoid. This is in agreement with the study by Arya SR et al., Buch AC et al., and Deepti SP et al., all of them showed pemphigus vulgaris to be the commonest entity among all vesiculobullous disorders followed by bullous pemphigoid $[9,10,13]$. Pemphigus vulgaris has no gender predilection, though in the present study, males were affected more than females. Out of 12 cases diagnosed as pemphigus vulgaris males were 7 (58.3\%) and $5(41.6 \%)$ were females, which probably reflects the higher male patients coming to dermatology OPDs in general.

In this study, 8 (22.2\%) cases correlated clinically and histopathologically with DIF patterns. Of the remaining 28 (77.7\%) patients, 5 (13.8\%) cases showed no antibody deposition, $21(58.3 \%)$ cases had no histopathological study, but correlated with clinical presentation and gave diagnostic findings with DIF, rest $2(5.5 \%)$ cases did not correlate with clinical features. Sensitivity $(88.8 \%)$ is similar in comparison to other studies by Kabir AKM Nurul et al., (88.23\%), Inchara YK et al., (73\%), and Minz RW et al., (70\%) showing high DIF sensitivity $[8,14,15]$. In the present study, lace like squamous intercellular pattern was noted in all types of pemphigus in concordance with study conducted by Chandrashekar $M$ et al., and Deepti SP et al., [Table/Fig-4,8], [13,16]. Current study described linear deposition of antibodies at dermo-epidermal juncton in bullous pemphigoid [Table/Fig-9] and CBDC. This was in concordance with study conducted by Kabir AKM Nurul et al., and Deepti SP et al., [8,13]. Present study showed granular deposition of antibodies at dermal papillae in Dermatitis herpetiformis. Buch AC et al., and Deepti SP et al., showed similar findings [10,13].

Majority of cases of pemphigus vulgaris showed $\operatorname{lgG}(66.6 \%)$ and C3 (33.3\%) deposition with $8.3 \%$ of cases showing IgM and IgA deposition each. This was similar to Arundhathi S et al., and Deepti SP et al., which showed $52.5 \%$ and $57.7 \%$ of IgG deposition in pemphigus vulgaris, respectively $[12,13]$. The intercellular deposition of $\operatorname{lgG}$ and $\mathrm{C} 3$ in epidermis in pemphigus vulgaris and pemphigus foliaceous is due to the localisation of target antigens (desmoglein 3, desmoglein 1) in the desmosomes [Table/Fig-10 a,b] [3]. Two cases (16.6\%) of pemphigus vulgaris were negative for DIF in this study. False-negative DIF in pemphigus has been reported in approximately $10 \%$ of specimens and may be due to technical error (e.g., by using wrong or weak antisera), presence of clinical or subclinical inflammation and blister formation within the biopsy specimen, or the use of a limited panel of antisera that does not include IgA antisera (for cases with IgA pemphigus). DIF may be "truly" negative in drug induced pemphigus. A truly negative DIF helps to rule out

\begin{tabular}{|c|c|c|c|c|c|c|c|c|c|}
\hline Diseases & $\lg G$ & $\operatorname{Ig} A$ & $\lg M$ & C3 & $\lg G+\lg A$ & $\lg G+C 3$ & $\lg G+\lg M+C 3$ & $\lg G+C 3+\lg A+\lg M$ & Negative \\
\hline PV & 4 & - & - & & 1 & 4 & & 1 & - \\
\hline $\mathrm{BP}$ & 1 & - & - & 1 & 1 & 1 & - & - & 2 \\
\hline CBDC & 1 & - & - & & 1 & & 1 & - & - \\
\hline Hansens disease & 1 & - & - & - & 1 & 1 & - & - & 1 \\
\hline $\mathrm{CP}$ & - & - & - & - & - & - & - & 1 & - \\
\hline $\mathrm{Bl}$ & - & - & - & - & - & - & 1 & - & - \\
\hline SJS & - & - & - & - & - & - & - & - & 1 \\
\hline PF & - & - & - & - & - & - & & 1 & - \\
\hline $\mathrm{DH}$ & 1 & - & - & - & 1 & - & - & - & - \\
\hline Linear IgA Pemphigoid & - & 1 & - & - & 1 & - & - & - & 1 \\
\hline BSLE & - & - & - & - & - & - & - & 1 & - \\
\hline Vasculitis & - & - & - & 1 & - & - & - & - & - \\
\hline Total (36) & $22.2 \%$ & $2.7 \%$ & - & $5.4 \%$ & $16.6 \%$ & $16.6 \%$ & $5.5 \%$ & $11.1 \%$ & $13.8 \%$ \\
\hline
\end{tabular}




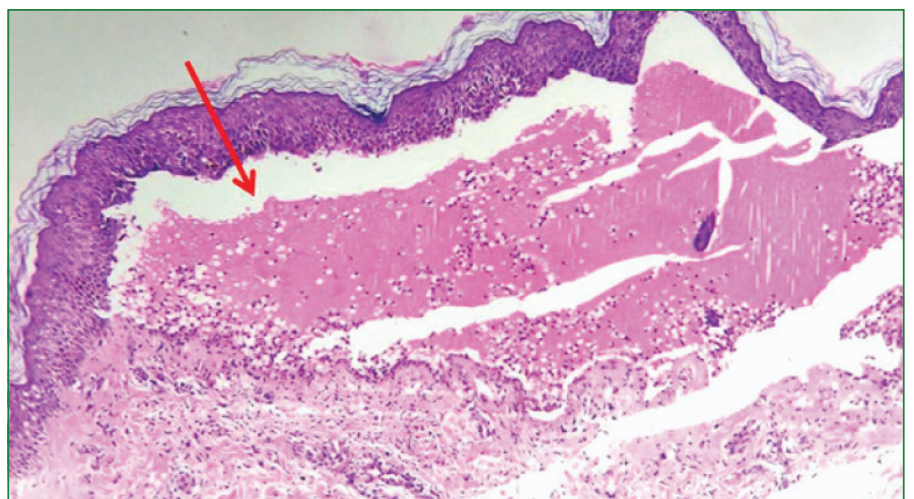

[Table/Fig-6]: Subepidermal bulla with neutrophils in Dermatitis herpetiformis, arrow marked (H\&E stain;100x).
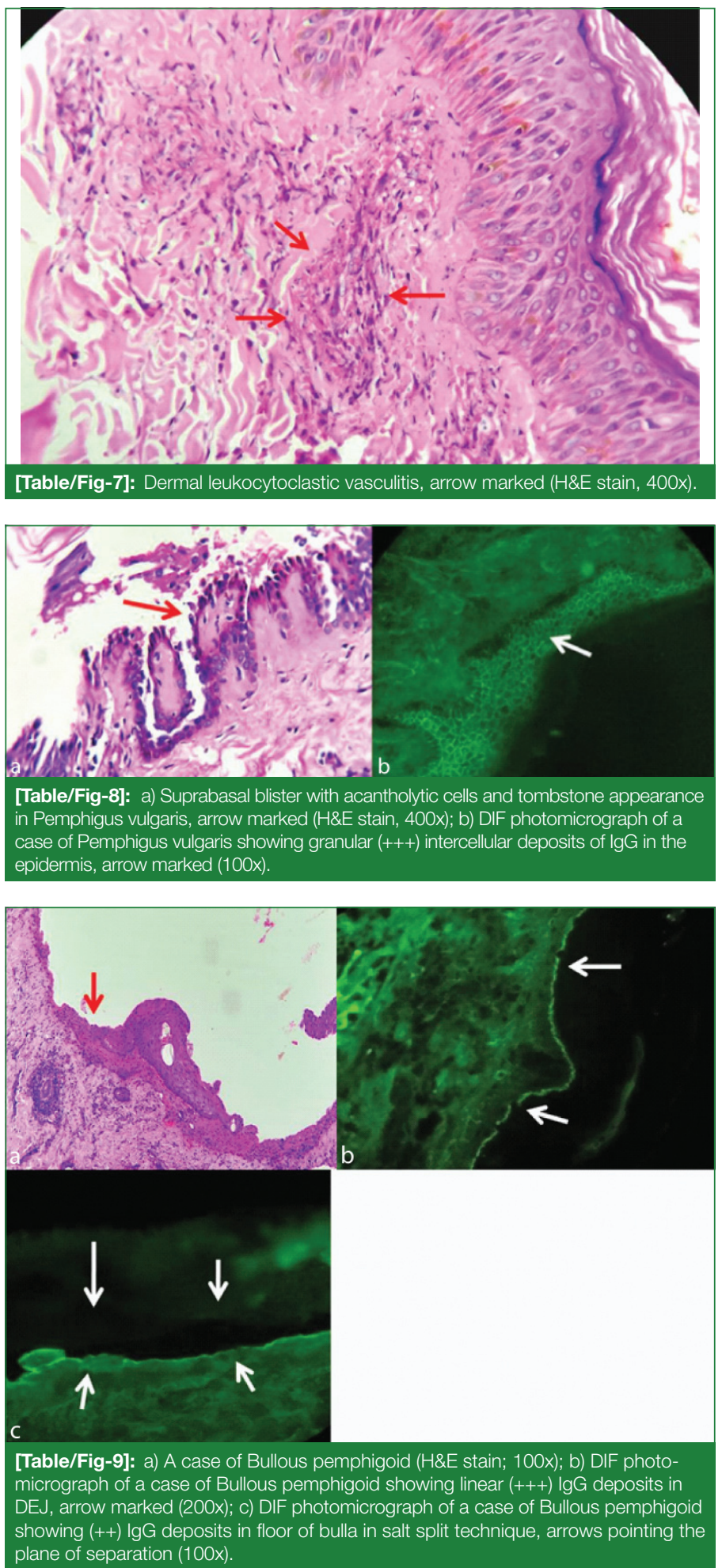

immunological basis of the disorder. The PPV of DIF in the diagnosis of pemphigus in the current study was $80 \%$ and NPV was $50 \%$.

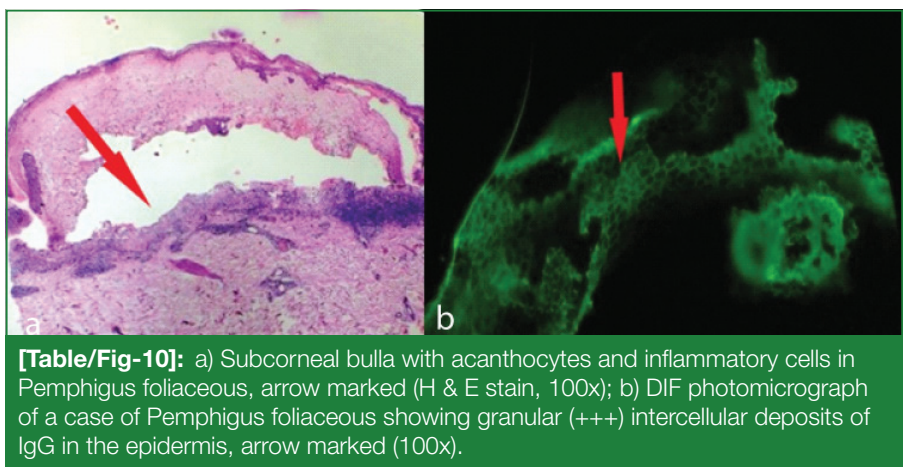

The PPV of DIF for pemphigus approaches 100\% and NPV is $85 \%$ to $90 \%$. Perhaps this was due to less number of cases in each disease group in this study and lack of proper histological correlation in some cases. In cases in which DIF is negative or nonspecific, but histopathology supports the diagnosis of pemphigus, the physician should repeat the test and/or do IIF to confirm the diagnosis [17]. Cases of bullous pemphigoid in present study showed C3, IgG and IgA deposition in $50 \%, 66 \%$ and $16 \%$ of the cases, respectively. The previous study by Kabir AKM Nurul et al., yielded variable results with $50 \%$ cases showed deposition of C3, 40\% cases showed C3 and $\operatorname{lgG}$, and $10 \%$ showed $\mathrm{C} 3$, IgG and $\lg \mathrm{M}$ along the $\mathrm{BMZ}$ [8].

\section{LIMITATION}

The limitation of the study is that the number of cases in each disease catagories is quite small. So we could not derive any significant statistical information from most of the disease entities except pemphigus vulgaris, and bullous pemphigoid. Also, in majority of cases $(77.7 \%)$, histopathological correlation was not available. So, further prospective large scale studies should be undertaken with histological correlation in all cases.

\section{CONCLUSION}

With proper sampling and prompt processing, DIF is an effective supplement to histology for accurate diagnosis of immune-mediated dermatological disorders. When the clinical features/ histopathology are inconclusive, diagnosis can be made on the basis of the DIF findings alone. DIF study not only distinguishes immune mediated bullous lesions from others, it is also definitive in some diseases, such as fish-net pattern of pemphigus and IgA positivity in linear $\lg A$ dermatosis. As combined analysis of clinical features, histopathology and DIF gives the best result. For the diagnosis of immuno-bullous cutaneous lesions, histology biopsy and DIF study should be advised in all cases.

\section{REFERENCES}

[1] Kanwar AJ, De D. Pemphigus in India. Indian J Dermatol Venereol Leprol. 2011;77(4): 439-49.

[2] Mohan KH, Pai S, Rao R, Sripathi H, Prabhu S. Techniques of immunofluorescence and their significance. Indian J Dermatol Venereol Leprol. 2008;74(4):415-19.

[3] Singla G, Yadav A, Ramesh V, Khunger N, Garg T. Vesiculobullous lesions and their relation to intensity of immunoglobulins and complement expression. Rec Adv Path Lab Med. 2015;1(2):31-35.

[4] Chhabra S, Minz RW, Saikia B. Immunofluorescence in dermatology. Indian J Dermatol Venereol Leprol. 2012;78(6):677-91

[5] Huilgol SC, Bhogal BS, Black MM. Immunofluorescence of the immunobullous disorders part one: Methodology. Indian J Dermatol Venereol Leprol. 1995;61:187-95.

[6] Vassileva S. Immunofluorescence in dermatology. Int $J$ Dermatol. 1993;32:153-61.

[7] Jindal A, Rao R, Bhogal BS. Advanced diagnostic techniques in autoimmune bullous diseases. Indian Journal of Dermatology. 2017;62(3):268-78.

[8] Kabir AKM Nurul, Kamal M, Choudhury AM. Clinicopathological correlation of blistering diseases of skin. Bangladesh Med Res Counc Bull. 2008;34:48-53.

[9] Arya SR, Valand AG, Krishna K. A clinico-pathological study of 70 cases of pemphigus. Indian J Dermatol Venereol Leprol. 1999;65(4):168-71.

[10] Buch AC, Kumar H, Panicker NK, Misal S, Sharma YK, Gore CR. A crosssectional study of direct immunofluorescence in the diagnosis of immunobullous dermatoses. Indian J Dermatol. 2014;59(4):364-68.

[11] Shafi M, Khatri ML, Mashina M, Ben-Ghazeil M. Pemphigus: A clinical study of 109 cases from Tripoli, Libya. Indian J Dermatol Venereol Leprol. 1994;60:140-43. 
[12] Arundhathi S, Raghunatha S, Mahadeva KC. A cross-sectional study of clinical, histopathological and direct immunofluorescence spectrum of vesiculobullous disorders. J Clin Diagn Res. 2013;7(12):2788-92.

[13] Deepti SP, SulakshanaMS, Manjunatha YA, Jayaprakash HT. A histomorphological study of bullous lesions of skin with special reference to immunofluorescence. Int J Curr Res Aca Rev. 2015;3(3):29-51.

[14] Inchara YK, Rajalakshmi T. Direct immunofluorescence in cutaneous vesicobullous lesions. Ind J Pathol Microbiol. 2007:50:730-32.
[15] Minz RW, Chhabra S, Singh S, Radotra BD, Kumar B. Direct immunofluorescence of skin biopsy: Perspective of an immunopathologist. Ind J Dermatol Venerol Leprol. 2010;76:150-58.

[16] Chandrashekar M, Leena JB, Vijay B, Sunila R, Manjunath GV. A clinicopathologica study of immunobullous lesions of the skin a two years study. Adv Lab Med Int. 2012;2(2):19-26.

[17] Diya F. Mutasim DF, Adams BB. Immunofluorescence in dermatology. J Am Acad Dermatol. 2001;45(6):803-24.

\section{PARTICULARS OF CONTRIBUTORS:}

1. Associate Professor, Department of Pathology, KIMS, Bhubaneswar, Odisha, India.

2. Additional Professor, Department of Dermatology and Venereology, AllMS, Bhubaneswar, Odisha, India.

\section{NAME, ADDRESS, E-MAIL ID OF THE CORRESPONDING AUTHOR:}

Dr. Sarojini Raman,

Department of Pathology, KIMS, Campus-5, Bhubaneswar-751024, Odisha, India.

E-mail: sraman10371@gmail.com

Date of Submission: Jun 15, 2019

Date of Peer Review: Jul 03, 2019

Date of Acceptance: Sep 04, 2019

FINANCIAL OR OTHER COMPETING INTERESTS: None.

Date of Publishing: Oct 01, 2019 